\title{
A symmetria vitruviana: \\ interpretação de Francesco di Giorgio \\ Martini em seu tratado \\ e obras construídas
}

\author{
Ana Paula Giardini Pedro*
}

\begin{abstract}
Resumo Francesco di Giorgio Martini (c. 1480-98) elabora método para concepção de templos, a partir de esquemas geométrico-proporcionais pautados por círculos e quadrados, alinhado às prescrições vitruvianas sobre symmetria e analogia arquitetura e corpo humano. Henry Millon e Richard Betts iniciaram estudos de cotejamento destes esquemas com obras e desenhos coevos. Interessa, aqui, continuar tais estudos aplicados às igrejas de San Bernardino degli Zoccolantie Santa Maria delle Grazie al Calcinanio, ambas atribuídas a Martini. Pretende-se responder lacunas apontadas pelos historiadores e demonstrar que, longe da repetição estereotípica, o método formulado por Martini concerne flexibilidade e adequação à diversidade de exigências impostas pela ideação arquitetônica, bem como avanço técnico e compositivo para superação das referências antigas e coetâneas.
\end{abstract}

Palavras-chave: Francesco di Giorgio Martini, symmetria vitruviana, tratados de arquitetura renascentista.

\section{La symmetria vitruviana: interpretación de Francesco di Giorgio Martini en su tratado y obras construidas}

Resumen Francesco di Giorgio elabora un método para con-
cebir templos, a partir de esquemas geométrico-proporcionales
constituidos por círculos y cuadrados, alineado con las prescrip-
ciones vitruvianas sobre symmetria y analogía entre arquitectura
y cuerpo humano. Henry Millon y Richard Betts iniciaron estu-
dios de comparación de estos esquemas con obras y diseños
coevos. Se presenta la continuación de esos estudios analizando
las iglesias de San Bernardino y Santa Maria delle Grazie, atri-
buidas a Martini. Se pretende explicar lagunas señaladas por
estos historiadores y demostrar que lejos de ser una repetición
estereotipada, el método elaborado por Martini presupone fle-
xibilidad y adecuación a la diversidad de requisitos impuestos
por la ideación arquitectónica, como por el progreso técnico y
compositivo para superar referencias antiguas y coetáneos.

Palabras clave: Francesco di Giorgio Martini, symmetria vitruviana, tratados de arquitectura renacentista.

\section{Vitruvian symmetria: Francesco di Giorgio Martini's interpretation in his treatise and erected buildings}

\begin{abstract}
Francesco di Giorgio Martini (c. 1480-98) elaborates a design method for temples, based on geometric-proportional schemes using circles and squares, related to the Vitruvian prescriptions on symmetria and the analogy between architecture and human body. Henry Millon and Richard Betts began studies comparing these schemes with coeval works and drawings. We intend to continue such studies applied to the churches of San Bernardino degli Zoccolanti and Santa Maria delle Grazie al Calcinanio, both attributed to Martini. Aiming to answer gaps pointed out by these historians and demonstrating that, far from stereotypical repetition, Martini's method concerns flexibility and adequacy to a diversity of requirements imposed by architectural ideation, as well as technical and compositional progress to overcome ancient and coeval references.
\end{abstract}

Keywords: Francesco di Giorgio Martini, vitruvian symmetria, renaissance architecture treatises. 
$\mathbf{N}$ segundo quartel do quattrocento Francesco di Giorgio interrompe a tradução do De Architectura vitruviano (Codici Zichy), a que se dedicava, e passa a reunir e organizar apontamentos para redação de seu tratado de arquitetura civil e militar (MUSSINI, 2003, p. XVII). Seus Trattati di Architettura e Arte Militare chegam ao nosso conhecimento em duas versões. Uma primeira muito vinculada ao texto antigo ${ }^{1}$, a qual é abandonada para formulação de nova composição, mais amadurecida².

Ainda que com maior autonomia em relação à tratativa vitruviana, já no prologo desta segunda versão dos Trattati, Martini adverte que para além de principal fonte literária, o De Architectura é referência primaz para a prescrição sobre as proporções de colunas templos e palazzi. Ele afirma adotar autonomia de invenção e engenho apenas nas formas e figuras apresentadas (MARTINI, 1967, p. 29 - M, f. 2r). Com efeito, já a primeira versão dos Trattatise apresenta assaz vinculada ao texto antigo. Nesta ocasião, ainda que tenha o livro de abertura dedicado às fortalezas, Martini enuncia aí os preceitos basilares de toda a tratativa. Referindo Vitrúvio, reitera a analogia macro-microcósmica entre corpo humano e cidade ou fortificação, rematando a passagem com prescrição que norteará o tratado:

"Portanto deve-se considerar que, assim como o corpo tem todos os membros correspondentes uns aos outros, e as partes com perfeita medida, também para as composições de templos, cidades, fortes e fortalezas se deve observar. "(MARTINI, 1967. p. 4 - T, f. 3r)

Passagem muito próxima à definição da symmetria vitruviana (VITRÚVIO. I, 2, 4) que incorre na justa relação métrica existente entre todos os componentes de uma obra completa, pensada na parte e no conjunto. Vitrúvio demonstra tal preceito através da analogia humana, ou seja, das descrições do Homo bene figuratus e do Homo ad circulum e ad quadratum, referências basilares na concepção, sobretudo, de templos (VITRÚVIO. III, 1, 4), mas também dos outros edifícios (VITRÚVIO. I, 2, 4). Por esta senda, Francesco di Giorgio afirma que a mesma coesão que ordena os membros no corpo humano, deve ser observada na concepção arquitetônica (MARTINI, 1967, p. 4, 20, 68-69 - T, f. 3r, 6v, 16v-17r), e apresenta esquemas geométricos constituídos por círculos e quadrados que devem nortear a delineação de edifícios e, assim, participar a perfeição deífica inerente ao homem (MARTINI, 1967, p. 301, 371, 414 - M, f. 3r, 30v, 46v).

* Ana Paula Giardini Pedro é Arquiteta e Urbanista, Professora da Pontifícia Universidade Católica de Campinas, ORCID <https://orcid.org/0000-0002-8036-4749>.

Longe da repetição estereotípica, estes esquemas de proporcionamento geométrico do edifício asseguram a universalidade, a adaptabilidade e a flexibilidade na ideação arquitetônica (.MONTEBELLO, 1997, p. 28) Na elaboração de seus trattati Martini enuncia, amiúde, a confiança no juízo e engenho do arquiteto. Juízo este que, pautado pelas regras da Arquitetura, deveria guiar a ideação mediante tantas variáveis que se apresentam nas diversas situações. Vale dizer: a observância ao contexto e 
1 Que corresponde aos códices Saluzziano 148 ou Torinese (da Biblioteca Reale de Torino - o qual é apresentado em edição de 1841, aos cuidados de Carlo Promi - MARTINI, 1841) e Ashburnamiano 361 ou Laurenziano (da Biblioteca Medicea Laurenziana de Florença).

2 Que corresponde aos códides S.IV. 4 (da Biblioteca Municipal de Siena) e Magliabechiano II.I.141 (da Biblioteca Nazionale de Florença - o qual é transcrito e anotado em edição de 1979, aos cuidados de Piero Marani MARTINI, 1979).

\footnotetext{
${ }_{3}^{3}$ Além do templo, Martini sugere, em rápida menção que também as casas de príncipes e grandes senhores deveriam seguir a ordem do corpo humano. (MARTINI, 1967. p. 72-73 - T, f. $17 \mathrm{v})$. Apesar de sucinta e pouco elucidativa, tal passagem assume particular relevo pois consta da primeira elaboração teórica que toca no liame arquitetura-corpo aplicado a um edifício residencial (WITTKOWER, 1971, p. 130, nota 4). Com efeito, na segunda versão do tratado, Martini apresenta esquemas geométricos que devem orientar a concepção dos edifícios civis equivalente aos que serão estudados a seguir e propostos para igrejas (MARTINI, 1967. p. 348-349 - M, f. 22r-22v; e tav. 203, 204). Sobre este método aritmo-geométrico de proporcionamento de residências privadas ver: MONTEBELLO, 1997, p. 22-27.
}

às demandas que ensejam a obra. A ilustrar tal multiplicidade de soluções, Martini apresenta, sem exaustão, quantidade considerável de desenhos e estudos gráficos para cada tema tratado.

Aqui, interessa investigar os desdobramentos destes esquemas geométricos - que remontam à symmetria vitruviana - nos desenhos sobre a moderna formação de templos apresentados nos Trattati, bem como nas igrejas de San Bernardino degli Zoccolanti em Urbino e Santa Maria delle Grazie al Calcinanio em Cortona. Com efeito, é intuito dar continuidade aos estudos demonstrados por Henry Millon, que em 1958 verifica a compatibilidade destes esquemas com a igreja de Cortona, bem como àquele desenvolvido por Richard Betts, que em 1993 amplia tal cotejamento aos desenhos do tratado e a outras igrejas, entre as quais as que são objeto deste estudo. Trata de revisão pontual que pretende responder duas das lacunas apontadas por estes autores.

O esforço de Martini quanto à fundamentação da similitude entre a arquitetura e o homem é empenhado na verificação gráfica por meio de desenhos em que são superpostos o corpo humano aos diferentes cosmos que estuda, seja a coluna, a cidade, mas principalmente os templos. Ao discorrer sobre estes últimos, o tratadista reitera o valor da concordância de cada um dos elementos que compõe a obra. Já na primeira versão de seu tratado, Francesco di Giorgio pondera:

"a meu ver, o que o edifício pode ter de mais excelente, é a concordância e conferência de cada coisa, ou seja, (...) entre um membro e outro. E assim, por conseguinte, que todas as partes tenham correspondência." (MARTINI, 1967. p. 48 - T, f. 12v)

No cerne da symmetria vitruviana, Martini recomenda que tal «concordância» seja consumada por meio de método aritmo-geométrico de proporcionamento que, na $1^{\text {a }}$ versão do tratado, é apresentando de forma incipiente, e é deslindado apenas naquela amadurecida. Para ideação de templos modernos, o tratadista sugere partir de esquemas geométricos compostos por quadrados e círculos que o amparavam na definição de todas as dimensões e asseguravam a consecução da coesão tal como no homo ad circulum e ad quadratum. ${ }^{3}$

Para Francesco di Giorgio os templos se dividem em três espécies formais, que orientam a invenção do arquiteto: a redonda, a angular ou em faces - referindo-se à retangular, e aquela que participa das duas anteriores, considerando mais perfeita a circular ou central (MARTINI, 1967, p. 372 - M, f. 31; 395 - M, f. 39). Para cada uma dessas espécies o tratadista prescreve esquemas de proporcionamento orientados por métodos distintos e específicos, todos com esteios nas figuras de quadrados, círculos e suas diagonais.

Para as elevações, Martini estabelece um esquema contido num quadrado (figura 1), em que semicírculos, diagonais e suas intersecções determinam largura e altura das naves, dimensões da porta principal, da lanterna, da cúpula e abóbadas (MARTINI, 1967, p. 399-400 - M, f. 40v-41). 
Figura 1: Esquema (01) para o proporcionamento de um "templo"em seção transversal. $\mathrm{Na}$ figura, de cima para baixo e da esquerda para a direita, lê-se: "Puteo; Cacumine della nave media; nave media; nave laterali; latitudine della porta; nave laterale". F onte: MARTINI, 1967, tav. $233-\mathrm{M}$, f. 41.

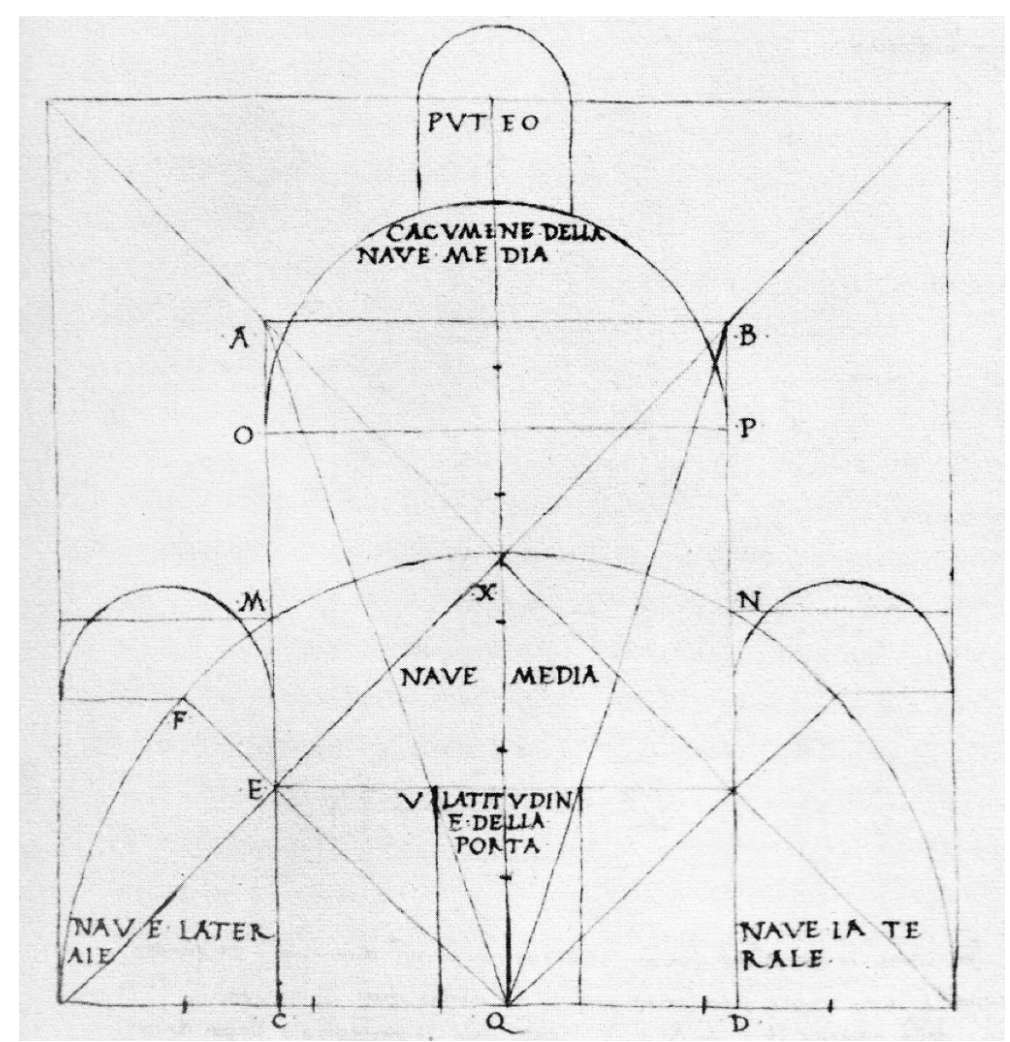

Para as plantas de templos longitudinais são apresentados dois esquemas. Um composto por dois quadrados de dimensões distintas, concêntricos, rotacionados em $45^{\circ}$, e inscritos um ao outro (figura 2). A completar o esquema, são aditados um terceiro quadrado de mesmo tamanho e adjacente ao menor, bem como um semicírculo que tem por diâmetro a linha de adjacência dos quadrados menores (MARTINI, 1967, p. 401 - M, f. 41-41v). O outro esquema (figuras 2A e 2C), Martini afirma ser equivalente ao primeiro e consta apenas do semicírculo e dos dois quadrados menores adjacentes (MARTINI, 1967, p. 401 - M, f. 41v). Ambos os esquemas de proporcionamento visam a determinação de módulo que definirá todo o edifício. A semelhança entre eles é assegurada pelo fato da obtenção do módulo, nos dois casos, seguirem o mesmo método. Ou seja, é definido pela altura da corda representada pelos segmentos $A B$ ou OS (destacado em verde nas figuras 2C e 2D).

O tratadista não aclara como tal unidade modular deveria ser articulada na concepção do templo, apenas verifica-se que no primeiro esquema de planta (esquema 02) fora adicionado, na porção inferior, um retângulo com altura equivalente ao módulo $A B$ (em verde - figura 2B). Ainda, os quadrados (em vermelho - figuras 2B e 2D) nos quais estão inscritas as diagonais QG e NT, assumem particular relevo, pois correspondem, respectivamente, a $1 / 5$ e 1/4 do comprimento de cada esquema (em azul - figuras 2B e 2D).

A orientar o desenho de edifícios sacros de planta central, Martini propõe um esquema geométrico a partir de dois quadrados concêntricos, rotacionados em $45^{\circ}$ (AECD e o periférico) que inscrevem dois círculos, além de diagonais e relativas paralelas formando retícula que orienta a colocação de semicírculos marginais (figura 3). 


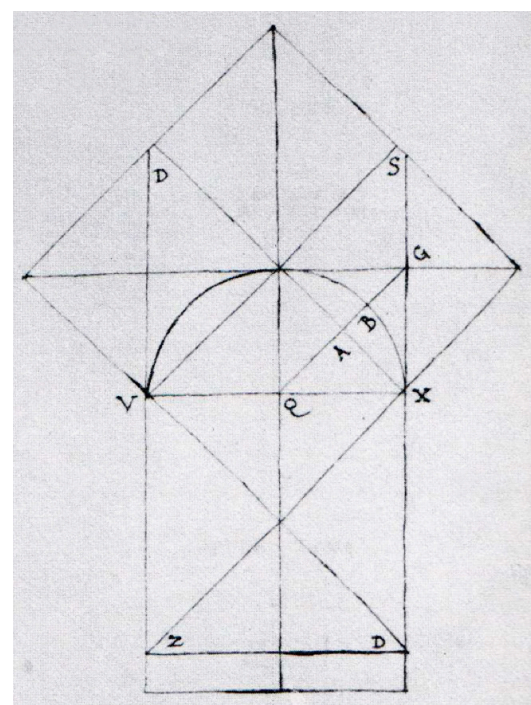

A

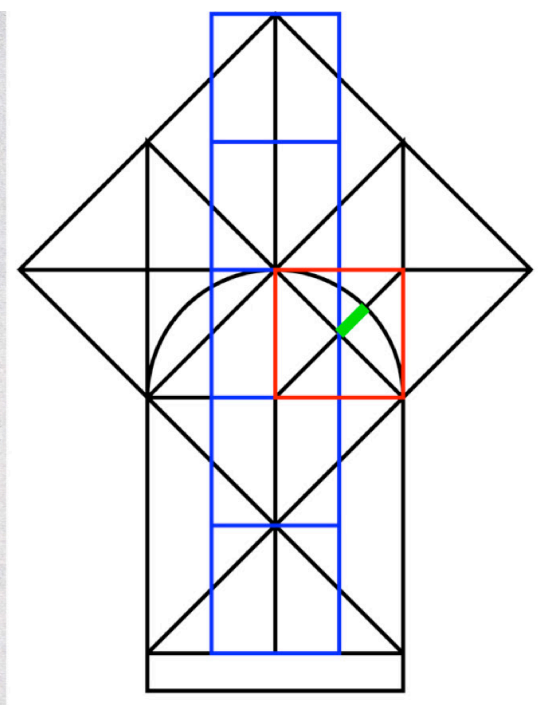

B

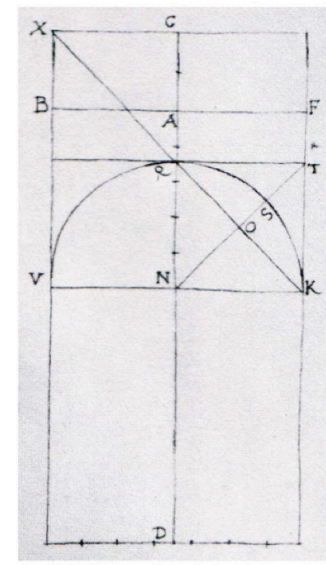

C

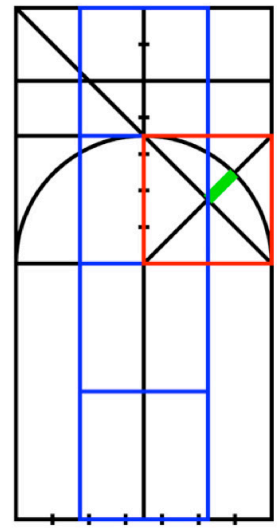

D

Figura 2 (acima): A - Esquema (02) para definição de unidade modular. Fonte: MARTINI,1967, tav. 234 - M, f. 41v;

B - Esquema (02) com destaque em vermelho para o quadrado QXG, em verde para o módulo $A B$ e em azul para a repetição (5x) do quadrado QXG. Fonte: adaptado de MARTINI,1967, tav. 234 - M, f. 41v;

C - Esquema (03) para definição de unidade modular. Fonte: MARTINI, 1967, tav. 234 - M, f. $41 \mathrm{v}$;

D - Esquema (03) com destaque em vermelho para o quadrado QNKT, em verde para o módulo OS e em azul para a repetição (4x) do quadrado QNKT. Fonte: adaptado de MARTINI,1967, tav. 234 - M, f. 41v.

Figura 3 (à direita): Esquema (03) para definição de templo com planta central. Fonte: MARTINI, 1967, tav. 235 - M, f. 42.

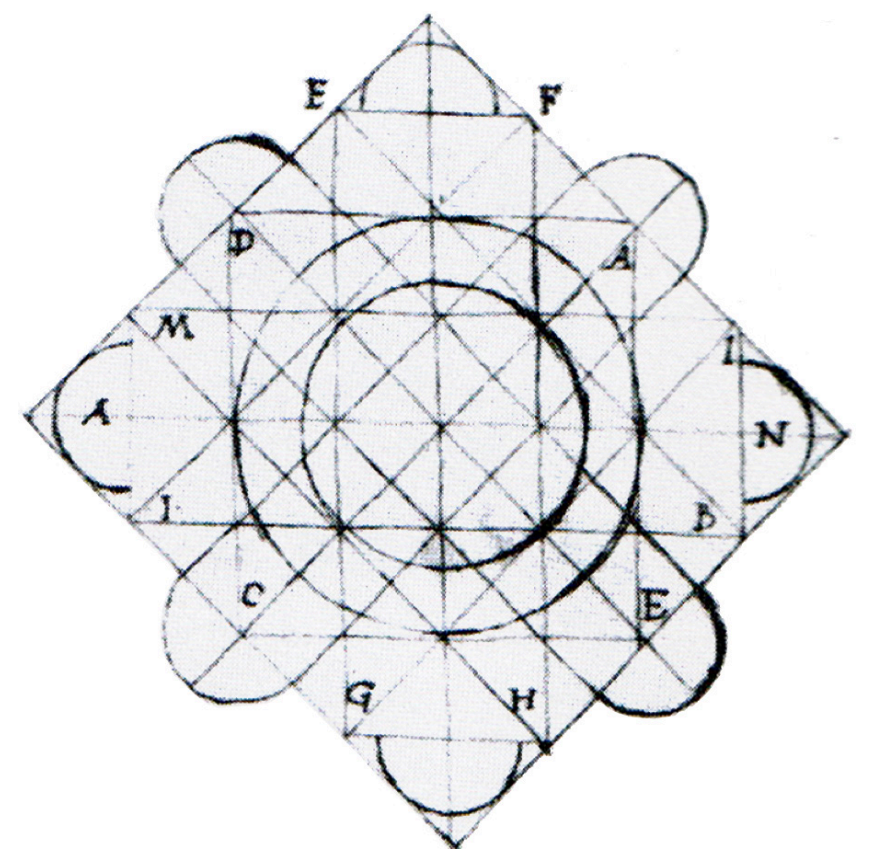


4 Tais métodos geométricos medievais referem-se aos estudos de Villard de Honnecourt.
Figura 4: A - Sobreposição dos esquemas de proporcionamento para igreja de planta central (em azul) associado àquele em faces ou longitudinal (em vermelho) e à planta proposta. Em rosa, a posição das capelas decorrentes de ajustes. Fonte: adaptado de MARTINI, 1967, tav. 236 - f. 42v;

B - Sobreposição do esquema de proporcionamento para igreja de planta em faces ou longitudinal à planta proposta. Fonte: adaptado de MARTINI, 1967, tav. 236 - M, f. 42v;

C - Sobreposição do esquema de proporcionamento para elevação de igreja em três naves elevação de igreja em nave simples. Em vermelho: trechos do esquema referentes à nave principal, aplicáveis a esta elevação. Em amarelo: trechos do esquema não aplicáveis ao desenho. Fonte: adaptado de MARTINI, 1967, tav. $228-$ M, f. 38v.
Todos estes esquemas geométricos que norteiam a definição de planta ou elevação do edifício podem remeter a procedimentos medievais ${ }^{4}$ de quadratura usados para calcular dimensões e formas estruturais (BETTS, 1993, p. 11; RYKWERT, 1996, p. 61; MILLON, 1958, p. 258). Não obstante, as constantes invocações à autoridade de Vitrúvio e ao conúbio edifício-homem sugerem o esforço de Martini em perquirir a geometria harmônica da figura humana, a symmetria vitruviana para o edifício. O que é corroborado pelos estudos de sobreposição dos desenhos à figura humana (MARTINI, 1967, p. 45 - T, f. 12).

Vale destacar que estes esquemas geométrico-proporcionais apresentados por Martini não são fixos ou inalteráveis, mas passíveis de variações por adição de módulos ou continuidade da sequência geométrica estabelecida. Como o próprio tratadista afirma:

"E figuras semelhantes, a partir desta forma e modo, podem ser variadas para se adaptarem às composições de templos." (MARTINI, 1967. p. 402 - M, f. 42)

É justamente essa autorização à variação oferecida pelo tratadista que fundamenta os estudos de cotejamento dos esquemas de proporcionamento com os desenhos dos Trattati e os edifícios por ele concebidos.

$\mathrm{Na} 2^{\mathrm{a}}$ versão do tratado, curiosamente, Martini apresenta apenas três desenhos de estudo a soluções de plantas e fachada de templos, todos assaz simplificados e sobrepostos à figura humana, seguindo razões proporcionais ora de 1:7 ora de 1:9 entre cabeça e altura total do corpo ou do edifício. Tratam de soluções diagramáticas às quais, naturalmente, tais esquemas são aplicados já com pequenas variações, destacadas em rosa e amarelo na figura 4, A B e C.

Henry Millon (1958, p. 259) aponta certas dificuldades para aplicação do esquema geométrico estabelecido por Martini, visto que existem pontos não estabelecidos quanto à espessura

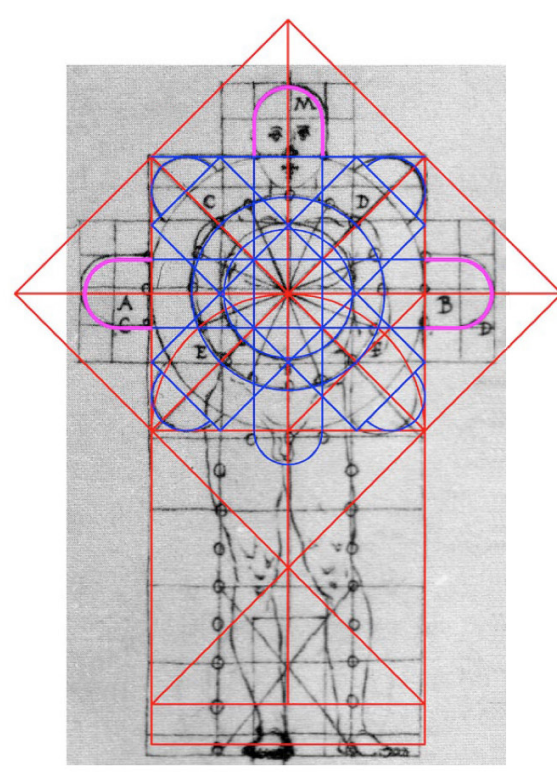

A

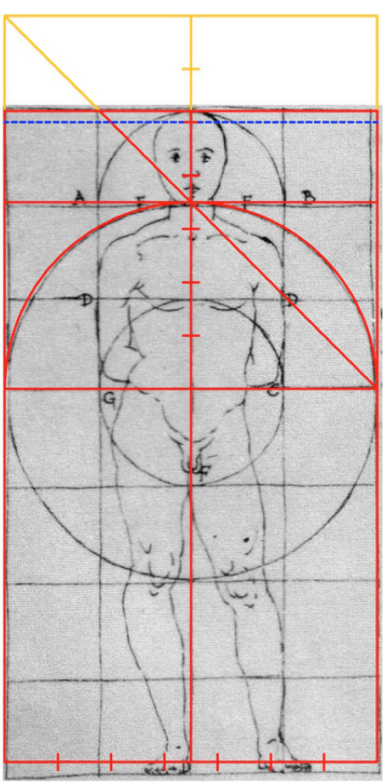

B

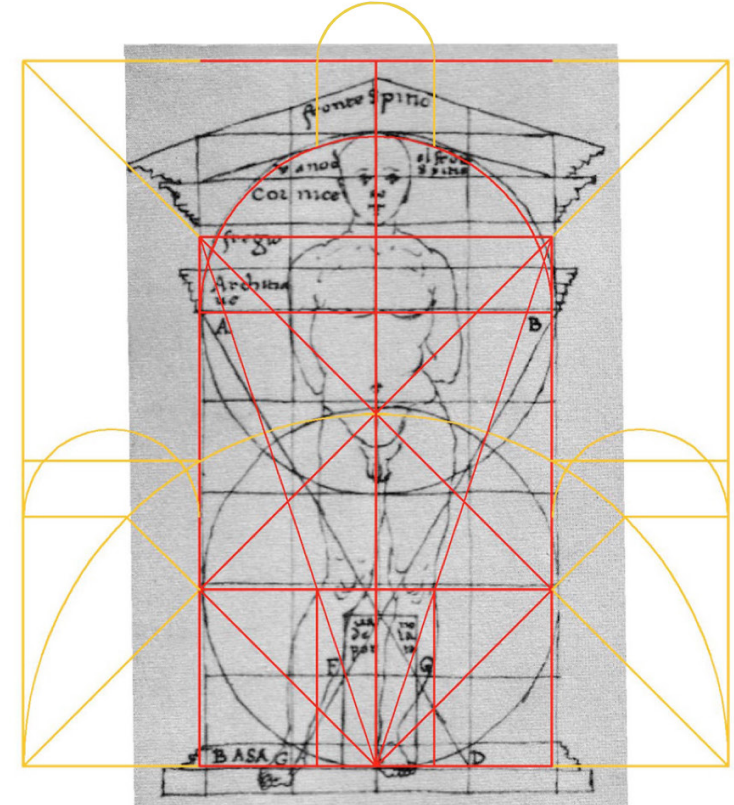

C 


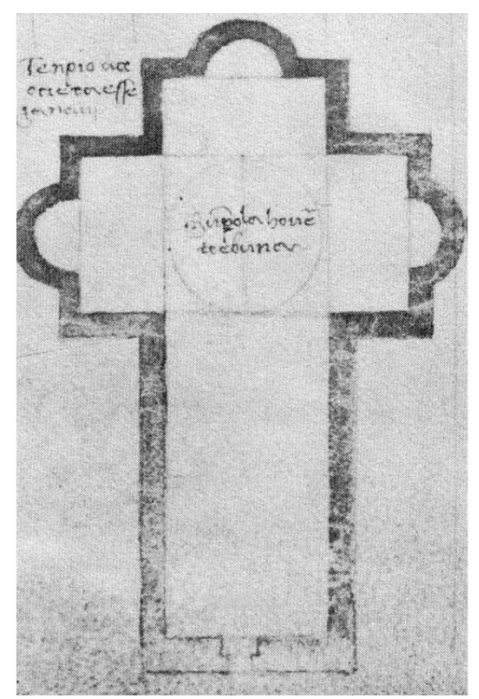

A

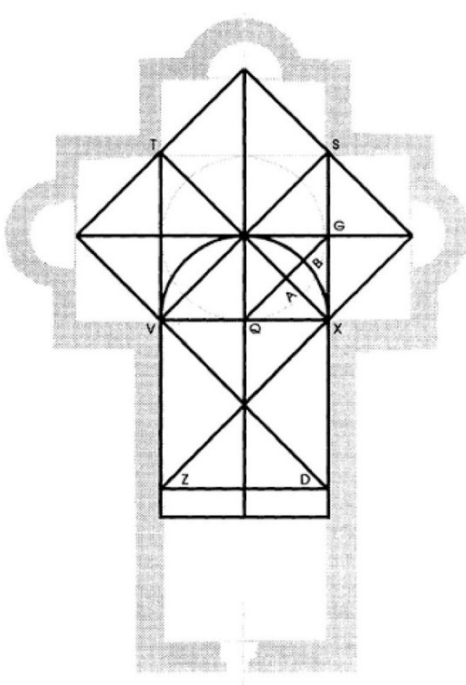

B

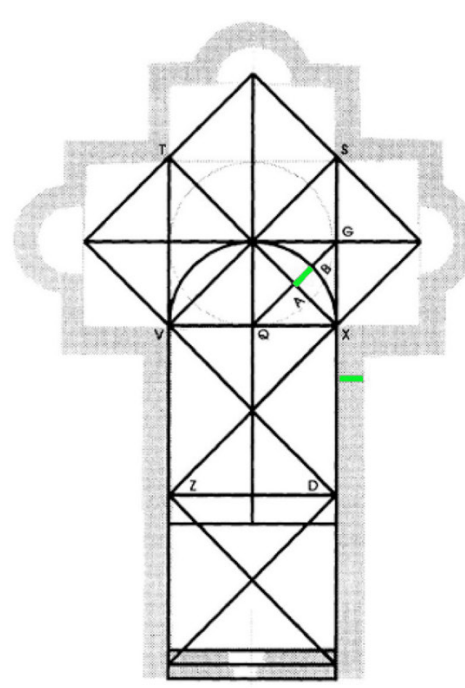

C
Figura 5: A - planta de templo em cruz, com nave única e cúpula. Fonte: MARTINI, 1967, tav. $18-\mathrm{T}$, f. $11 \mathrm{v}$;

$B$ - método geométrico [esquema 02] para concepção de igreja sobreposto a planta de templo em cruz, com nave única e cúpula. Fonte: BETTS, 1993, p. 13, Fig.8;

C - Variação do método geométrico [esquema 02] para concepção de igreja sobreposto a planta de templo em cruz, com nave única e cúpula. Fonte: BETTS,1993, p. 13, Fig.9. dos muros e o respectivo posicionamento em relação à trama ortogonal, ou seja, se em eixo ou faceando as linhas da trama. Soma-se ainda o fato de Martini ter incluído, apenas nessa passagem, número reduzido de estudos gráficos de plantas e fachada de templo. De outro lado, a postura lacônica do tratadista corrobora seu intento de não apresentar modelos fechados, sugerindo possibilidade de variação e flexibilidade inerentes à ideação arquitetônica, e sua confiança no bom juízo do arquiteto para esquadrinhar a melhor solução em cada caso específico.

A chave para deslindar tais lacunas fora sugerida por Millon (1958, p. 259, nota 14), ao reconhecer pistas nos desenhos de templos da versão inicial do tratado. A questão é superada por Richard Betts (1993), que se dedicou ao estudo sistemático de tais soluções gráficas. Este último aponta que os esquemas proporcionais apresentados por Martini na $2^{a}$ versão do tratado, além de definirem parâmetros para soluções compositivo-formais das novas igrejas, estabelecem um método de dimensionamento estrutural para muros portantes em função do vão que cúpulas e abóbadas devem vencer.

Betts (1993, p. 9-17) elucida, então, que tais esquemas determinam as dimensões internas da igreja, e a espessura das paredes é descrita pela altura da corda dos semicírculos, a referida unidade modular dos esquemas já vistos (figura 2 ) ou equivalentes derivações. A confirmar sua hipótese, Betts afirma ter se dedicado ao cotejamento dos esquemas de proporcionamento geométrico apresentados na versão amadurecida do tratado com as mais de 30 plantas de templos desenhadas na $1^{\text {a }}$ versão, exemplificando tal empenho com as verificações atinentes a dois destes desenhos.

O primeiro exemplo, uma planta em cruz latina (figura 5, A) cujas medidas internas dos braços do transepto e do coro correspondem à dimensão do quadrado maior e rotacionado do esquema (figura 5, B). A nave tem comprimento estabelecido pela variação deste esquema, sendo adicionado quadrado adjacente ao VXDZ. A validação é rematada pela correspondência da altura da corda $A B$ e a espessura do muro (em verde na figura 5, C). 
5 "E porque as faces dos templos são tiradas do corpo humano com aquelas razões e medidas que este requer, aqui as exporei. Deve-se saber que o corpo humano é dividido em 9 partes ou 9 cabeças, desde o término e caimento da fronte e cabelos até a extremidade do queixo. E na transversal, no sentido dos braços [abertos], outras 9 partes, das quais se extrai $4 \frac{1}{2}$, entre um e outro cotovelo. E assim como a altura do corpo é 9 cabeças, também a face do templo deve ter ... continua na página 34 ..

Figura 6: A - Planta de templo alongado com nave em 3 quadros. Fonte: MARTINI, 1967, tav. 18 - T, f. 11v;

B - Esquema (02) para definição da unidade modular, com destaque em azul para referências usadas por Betts. Fonte: adaptado de MARTINI, 1967, tav. 234 - M, f. 41v;

C - Método geométrico [esquema 02, em azul] para concepção de igreja sobreposto à planta de templo alongado com nave em 3 quadros. Fonte: adaptado de BETTS, 1993, p. 14, Fig 8;

D - Variação do método geométrico [esquema 02, em vermelho] para concepção de igreja sobreposto à planta de templo alongado com nave em 3 quadros. Fonte: adaptado de BETTS, 1993, p. 13, Fig 9.

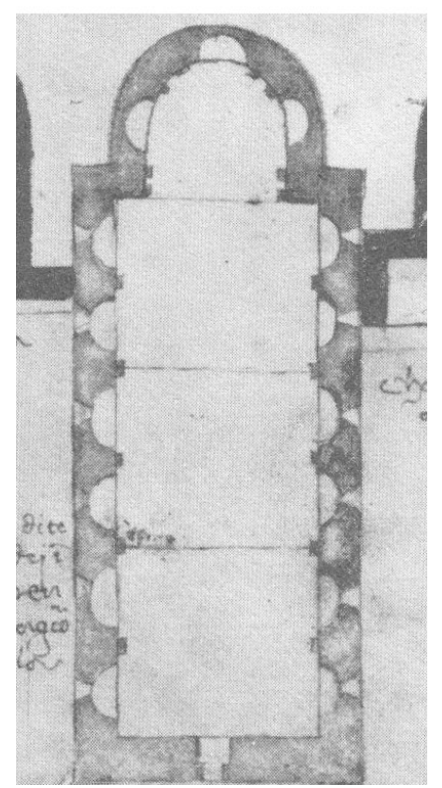

A

O outro exemplo apresentado por Betts parte da planta de templo alongado (figura 6, A), em que o diâmetro do semicírculo do esquema (em azul na figura 6, B e C) define a largura interna da nave. A continuidade de mesma lógica geométrica, vale dizer, um passo adiante na sequência de rotação e circunscrição do quadrado e semicírculo (em vermelho na figura $6, D$ ), define a largura externa da igreja e a nova unidade modular $A^{\prime} B^{\prime}$ (em vermelho mais grosso) corresponde a espessura do muro, ratificando então a validade da variação.

Betts (1993, p. 10, nota 20) aponta ainda que apenas dois desenhos apresentados na $1^{\text {a }}$ versão do tratado não teriam respeitado os esquemas geométricos. Um, referente a planta de templo em cruz latina circunscrita ao corpo humano (figura 7). No entanto, estudando a variação do esquema por método um pouco divergente daquele apresentado pelo historiador (BETTS, 1993, p. 13-14), é possível verificar concordância inclusive aí. Aditando dois outros quadrados, consecutivamente circunscritos e rotacionados verifica-se a largura total do transepto. No vértice inferior do maior quadrado, é adicionado mais um quadrado igual ao Q' $G^{\prime} X^{\prime}$ (figura 7), e o retângulo que remata a porção inferior do esquema inicial é deslocado para baixo, concluindo o comprimento total da igreja. Tendo como referência um novo semicírculo, define-se novo módulo $A^{\prime} B^{\prime}$, que corresponderá à espessura do muro (figura 7). Esta, uma revisão ao estudo de Betts que, por outro lado, corrobora seu argumento central.

O outro desenho é aquele com a elevação de templo em três naves também circunscrita a figura humana (figura 8). Em texto Martini afirma que a altura total do frontispício deveria corresponder a sua largura, ${ }^{5}$ em equivalência a symmetria do homo ad quadratum vitruviano. Contudo o desenho não corresponde ao texto. É sensível a diferença entre a altura e a largura. Restituindo o esquema geométrico estabelecido para fachada de templos, verifica-se que apenas as larguras conferem, mas as alturas não respondem ao respectivo esquema de proporcionamento (em vermelho na figura 8). As alturas da porta principal, dos pés-direitos das naves central e laterais, bem como da cúpula são consideravelmente distintas da indicação do esquema.

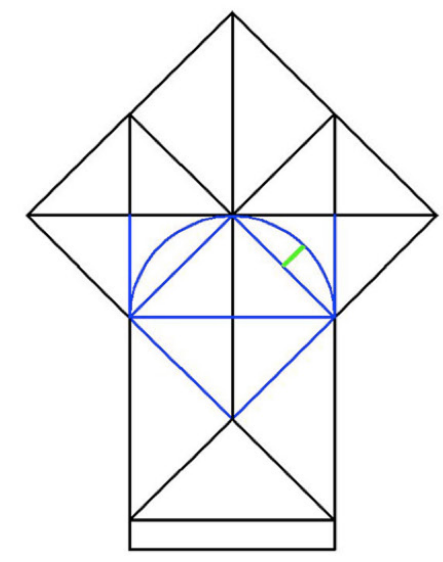

B

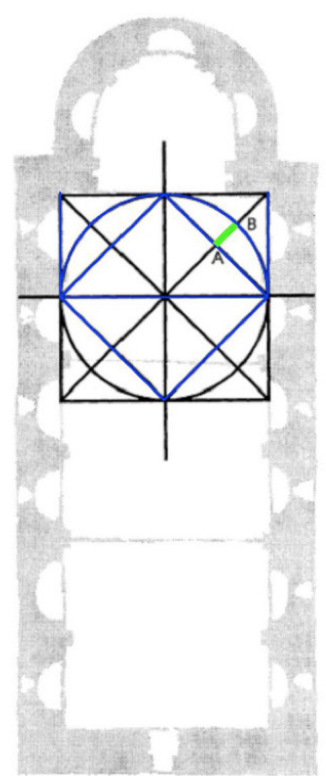

C

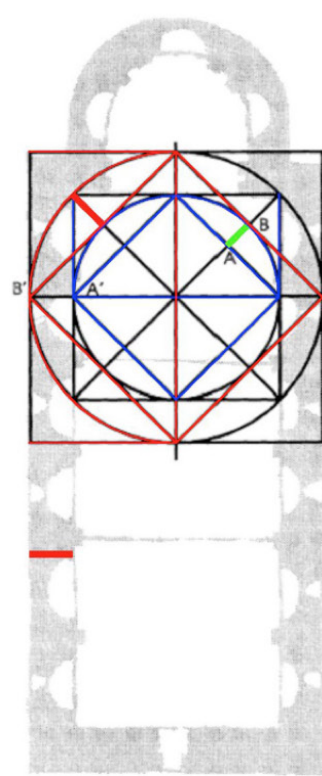

D 
Figura 7 (topo): Analogia entre templo e corpo humano com verificação do esquema de proporcionamento aplicado à planta da igreja. Em azul, o esquema tal como descrito por Francesco di Giorgio. Em vermelho, a variação do esquema. No desenho, acima e à esquerda, lê-se: "proportione di tenpi sichondo el chorpo humano". Fonte: adaptado de MARTINI, 1967, tav. $18-$ T, f. 11v.

Figura 8 (embaixo): Fachada de templo com três naves sobreposta ao esquema de proporcionamento para elevação de igreja. Na figura, à esquerda, lê-se: "Misura dela faccia del tenpio hovero basiliche". Fonte: adaptado de MARTINI, 1967, tav. $38-T$, f. 21V.
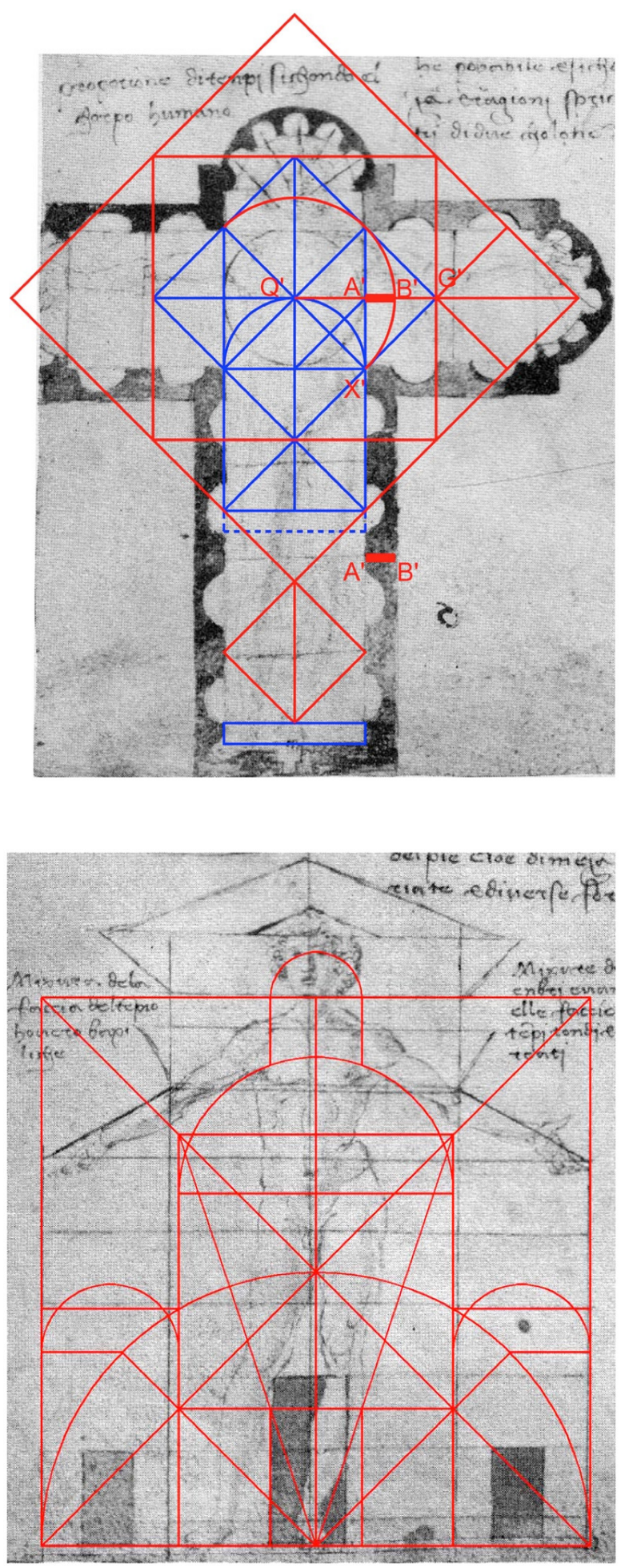
... continuação da nota 5 ... sua altura dividida em 9 partes, e sua largura em $4 \frac{1}{2}$ partes, assim como são $4 \frac{1}{2}$ partes de uma junta do cotovelo à outra. O resto, até a extremidade dos dedos, se atribui às outras naves que devem ladear, que equivalem à $2 \frac{1}{2}$. As portas dessas naves devem ser altas em proporção com sua largura. A altura e vão da porta do corpo do meio, com $2 \frac{1}{2}$ das 9 partes, ou seja, com altura correspondente à altura do joelho à planta dos pés. A base deste templo deve ter de altura a do pé, isto é, $1 / 2$ cabeça." (MARTINI, 1967, p. 91 - T, f. 21v).

Figura 9 (acima): A - sobreposição do esquema de proporcionamento à planta de San Bernardino degli Zoccolanti, em sua conformação original. Fonte: BETTS, 1993, p. 16;

B - acréscimo da variação do esquema de proporcionamento. Fonte: BETTS, 1993, p. 16.

Figura 10 (á direita): Sobreposição de variação esquema de proporcionamento à planta de Santa Maria del Calcinaio. Fonte: BETTS, 1993, p. 17, fig. 17.

Richard Betts avança seu estudo de cotejamento dos esquemas geométricos também com as plantas das igrejas de San Bernardino de Urbino e Santa Maria al Calcinaio de Cortona, ambas atribuídas a Francesco di Giorgio. Aqui, o historiador segue a mesma lógica de variação esquemática já apresentada, como se pode verificar nos estudos gráficos em que superpõe as plantas destas igrejas e o esquema martiniano com as respectivas variantes (figuras 9 e 10). Novamente, as unidades modulares resultantes da variação, nomeadas $A^{\prime} B^{\prime}$ em ambos os casos, validam tal cotejamento pela correspondência com a espessura do muro em cada uma das igrejas.

Betts (1993) concentra seu estudo na verificação estritamente de plantas. Mas, anteriormente, Henry Millon (1958) houvera se dedicado a esta verificação de aplicabilidade dos esquemas geométricos do tratado à Santa Maria del Calcinaio, incluindo então os estudos para a fachada.

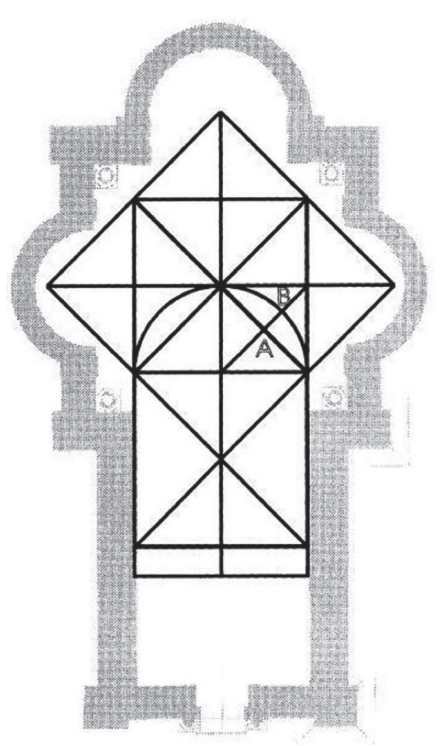

A

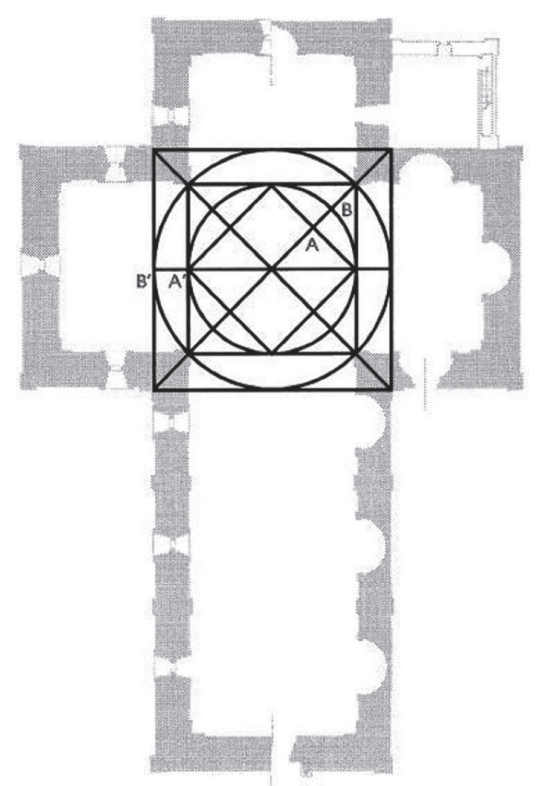

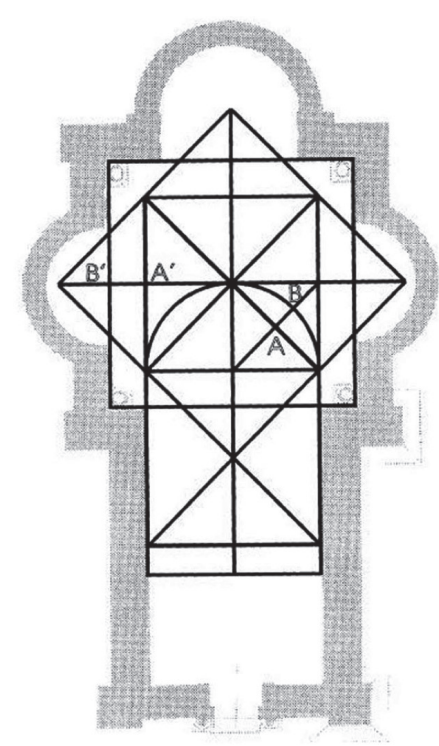

B 
Figura 11: A - Planta de Santa Maria delle Grazie al Calcinaio sobreposta ao desenho martiniano para templo de planta composta (alongada + central). Fonte: apresentado em MARTINI, 1967, tav. 236 - M, f. 42v.;

B - Elevação de Santa Maria delle Grazie al Calcinaio sobreposta ao desenho martiniano para frontispício de templo em nave simples. Fonte: apresentado em MARTINI, 1967, tav. $228-\mathrm{M}$, f. 38v. (adaptado de: MILLON, 1958, figs. 5 e 6 ).

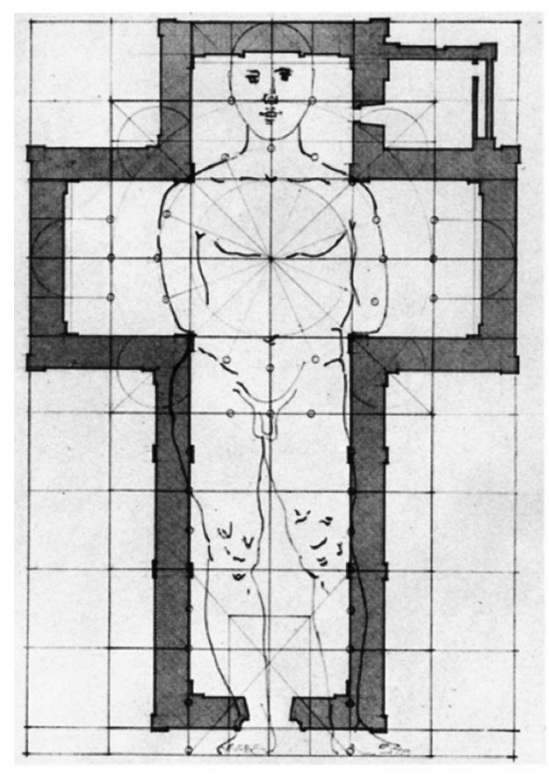

A

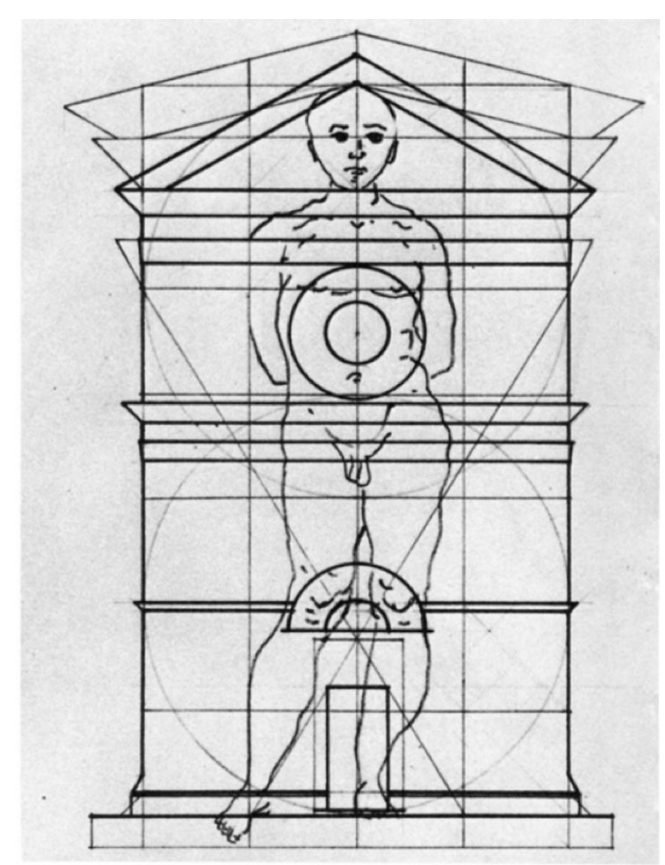

B
Na ocasião, Millon (1958, p. 260) sobrepõe a planta da igreja de Cortona à solução diagramática de planta de templo composto (central e em faces, simultaneamente), e como bem assevera o historiador, a "correspondência é precisa demais para ser acidental" (figura 11, A). Ainda assim, ele admite algumas disparidades na igreja construída, tais como a ausência de naves laterais, a cúpula que não se apoia num anel de colunas e a dimensão reduzida do nicho existente em relação ao semicírculo da abside proposta no tratado. Cabe interpretar tais diferenças como adaptações inerentes às demandas de contexto específico, cerne da tratativa martiniana que prescreve flexibilidade.

Em relação à fachada, a superposição é articulada com a solução diagramática de fachada de templo (figura 11, B). Aqui também há estreita correspondência dos dois desenhos, e entre as divergências têm-se: o entablamento com 3/4 do módulo e não com 1 e 1/2, como prescrito; o oculum em relação a malha modular; e a dimensão da porta de ingresso.

Sobre a última divergência, cabe revisão. Tendo em mente que Martini propõe um entablamento completo dividindo a altura total da fachada da igreja construída, pode-se considerar uma variação também no esquema. Destaco, pois, novas diagonais conformando a porta de ingresso, ou seja, linhas que partem dos mesmos pontos da base alcançando as extremidades inferiores do entablamento intermediário (em verde na figura 12, A e B). A validar tal possibilidade, observa-se que estas novas diagonais correspondem a linhas horizontais existentes no esquema geométrico atinente a fachada, como se vê na convergência das linhas verdes em direção às amarelas - se encontrando - (na figura 12, A), e ainda a razão 1:2 entre largura e altura da porta, tal como sugerido no tratado. 
6John Spencer (1958, p. 14-15) aventa ainda a possibilidade de haver ecos dos estudos filaretianos quanto às igrejas de planta centralizada quadradas nas proposições de Leonardo da Vinci. Por esta senda destacase o desenho leonardesco ao centro e à direita do foglio $25 \mathrm{v}$ do Manuscrito B e o segundo templo de Plusiapolis (tav. 89, f. 119v de seu Trattato di Architectura).

7 Para um estudo sobre a repercussão do esquema proporcional proposto por Francesco di Giorgio para a concepção de igrejas de planta central nos estudos de Leonardo da Vinci, Bramante, entre outros ver: BETTS, 1993, p. 18-25.

Figura 12: A - Sobreposição do esquema de proporcionamento para elevação de igreja com três naves à elevação de igreja em nave simples. Em verde: novas diagonais de referência; em verde tracejado: correspondência da intersecção das novas diagonais de referência e altura da porta na fachada de Santa Maria delle Grazie al Calcinaio. Fonte: adaptado de MARTINI, 1967, tav. 228 - M, f. 38v.;

B - Sobreposição da elevação de igreja em nave simples ao desenho fachada de Santa Maria delle Grazie al Calcinaio. Em verde: novas diagonais de referência; em verde tracejado: correspondência da intersecção das novas diagonais de referência e altura da porta na fachada da referida igreja. Fonte: adaptado de MILLON, 1958, fig. 6; MARTINI, 1967, tav. $228-$ M, f. 38v.
Essas revisões pontuais aos estudos de Betts e Millon, antes corroboram o argumento central que cada historiador desenvolve: ambos ultimando a convergência entre as prescrições teóricas elaboradas nos Trattati e sua aplicação nas obras executadas de Francesco di Giorgio. Mais ainda, ao verificar que os esquemas geométricos, para além de nortearem os estudos proporcionais que definem formalmente tais edifícios, constam também de método para solucionar demandas estruturais quanto à espessura de muros portantes, pode-se inferir que Martini está atento à relação inescusável inerente à tríade vitruviana: firmitas, utilitas e venustas (VITRÚVIO. I, 3, 2).

Ademais, não se pode deixar de apontar a similitude com os célebres estudos para igreja de planta centralizada em quincunce, desenvolvidos no Manuscrito ${ }^{6}$ (foglio $17 v$ e $25 \mathrm{v}$ ), de Bramante para Basilica de São Pedro ${ }^{7}$ nos quais estes arquitetos parecem ter assimilado o esquema geométrico de proporcionameto proposto por Francesco di Giorgio. Nos estudos leonardescos verificam-se claramente o perímetro quadrado circunscrito por capelas semicirculares, cujas plantas parecem ter derivado diretamente do estudo geométrico martiniano.

Enfim, Trata de um método para nortear a concepção de edifícios que implica em flexibilidade e adequação a cada contexto específico, que não perde de vista o cerne da symmetria e do decor vitruvianos. Francesco di Giorgio, longe de prescrever soluções ideais, está sim atento às demandas concretas, e às possibilidades de avanço técnico e compositivo em prol da emulação, da superação das referências antigas e coetâneas.

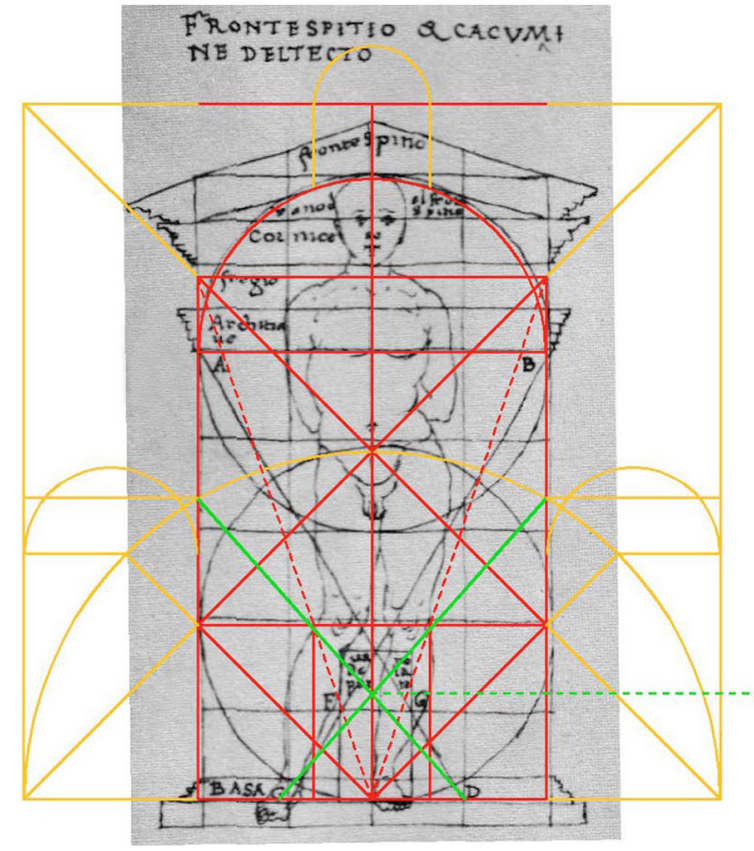

A

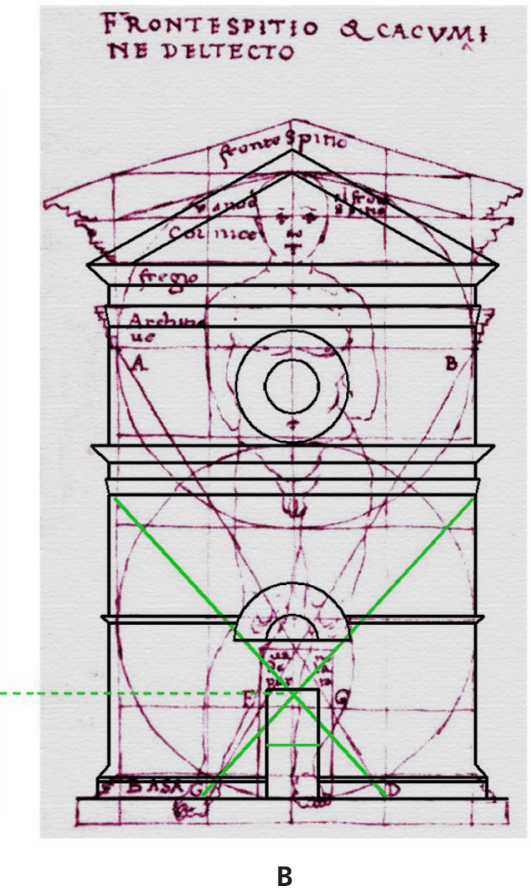




\section{Referências bibliográficas}

BETTS, Richard J. Structural innovation and structural design in Renaissance Architecture. The Journal of the Society of Architectural Historians, California, v. 52, n. 1, mar, p. 5-25, 1993.

MARTINI, Francesco di Giorgio. Trattato di Architettura Civile e Militare di Francesco di Giorgio Martini Architetto Senese del Secolo XV ora per la prima volta publicato per cura del Cavaliere Cesare Saluzzo con dissertazioni e note per servire alla storia militare italiana. (Dal codice Membranaceo della Biblioteca di S. E. Il Cav. Cesare saluzzo) A cura di Carlo Promis. Torino: Tipografia Chirio e Mina, 1841.

Trattati di Architettura, Ingegneria e Arte Militare. A cura di Corrado Maltese. Trascrizione di Livia Maltese Degrassi. Milano: II Polifilo, 1967.

MARTINI, Francesco di Giorgio. // codice Ashburnham 361 della Biblioteca Medicea Laurenziana di Firenze: Trattato di Architettura. Presentazione di Luigi Firpo; Introduzione, trascrizione e note di Pietro C. Marani. Firenze: Giunti Barbèra, p. XI-XXVIII, 1979.

MILLON, Henry. The Architectural theory of Francesco di Giorgio. The Art Bulletin, New York, v. 40, n. 3, Sept, p. 257-261, 1958.

MONTEBELLO, Mario. Francesco di Giorgio Martini: teoria e pratica proporzionale da Giulianova ai Trattati. Teramo: Demian Edizioni, 1997.

MUSSINI, Massimo. Francesco di Giorgio e Vitruvio: Le traduzioni del "De Architectura" nei Codici Zichy, Spencer 129 e Magliabechiano II.I.141. Firenze: Leo S. Olschki, 2003.

RYKWERT, Joseph. The dancing column: on order in architecture. Cambridge: MIT press, 1996.

SPENCER, John Richard. Filarete and the Central Plan Architecture. The Journal of the Society of Architectural Historians, California, v. 17, n. 3, Aut, p. 10-18, 1958.

VITRÚVIO. Tratado de Arquitectura. Tradução do Latim, introdução e notas por M. Justino Maciel. Lisboa: IST Press. 2006

WITTKOWER, Rudolf. Architectural Principles in the Age of Humanism. London: W. W. Norton \& Company, 1971. 